\title{
Multiple endocrine neoplasia type 2B (mucosal neuroma syndrome, Wagenmann-Froboese syndrome)
}

\author{
P J Morrison, N C Nevin
}

\section{Department of Medical Genetics, Belfast City Hospital Trust, Lisburn Road, Belfast, BT9 7AB, UK P J Morrison N C Nevin \\ Correspondence to: Dr Morrison.}

\begin{abstract}
Multiple endocrine neoplasia type 2B (MEN 2B), or the mucosal neuroma syndrome, is an autosomal dominant hamartoneoplastic syndrome. Features include multiple mucosal neuromas, phaeochromocytoma, medullary thyroid carcinoma, and Marfanoid body habitus with a characteristic dysmorphic facies. The gene responsible is the receptor tyrosine kinase (RET) proto-oncogene on chromosome 10. The mutational spectrum of MEN $2 B$ is remarkably narrow, with over $95 \%$ of cases being caused by a single methionine to threonine substitution in the intracellular tyrosine kinase domain. Recent biochemical evidence suggests that this mutation alters the substrate specificity of intracellular signal transduction.

(F Med Genet 1996;33:779-782)
\end{abstract}

Key words: multiple endocrine neoplasia type $2 \mathrm{~B}$; mucosal neuroma syndrome; Wagenmann-Froboese syndrome.

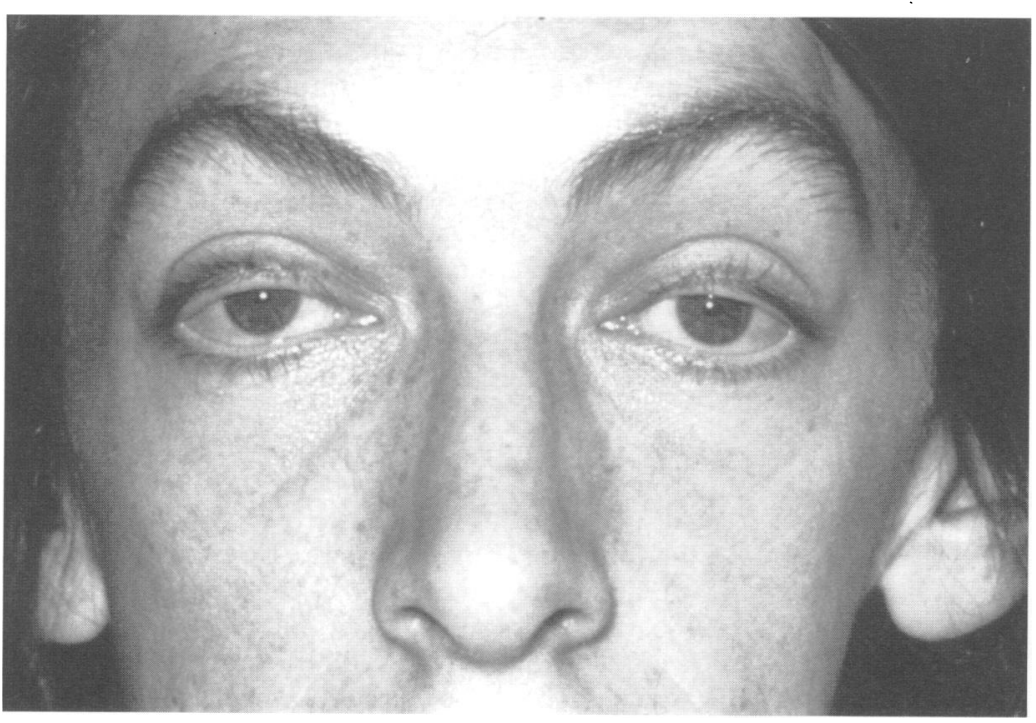

Figure 1 The upper face in MEN 2B showing thickening and eversion of the upper eyelid margins and prominent eyebrows.
Multiple endocrine neoplasia type 2B (MEN 2B) was described initially by Wagenmann ${ }^{1}$ and Froboese. ${ }^{2}$ Others, including Williams and Pollock ${ }^{3}$ and Gorlin and Vickers, ${ }^{4}$ have delineated the expanded phenotype. As in other hamartoneoplastic syndromes, autosomal dominant inheritance has been shown. MEN 2B, along with MEN $2 \mathrm{~A}$ and familial medullary thyroid carcinoma (FMTC), are caused by mutations in the RET proto-oncogene on chromosome 10. MEN 2B differs from MEN $2 \mathrm{~A}$ and FMTC, however, in that it is characterised by additional neuroendocrine abnormalities. The features of the three conditions are shown in table 1 .

\section{Clinical features}

MEN 2B has a characteristic phenotype with medullary thyroid carcinoma (MTC) and phaeochromocytoma. The face may give a wide eyed expression with thickening and eversion of the upper eyelid margins and visible tarsal plates (fig 1). Neuromas may be present on the eyelids and conjunctiva, and prominent thickened corneal nerves that extend to the pupillary area may be seen on slit lamp examination. ${ }^{5}$ The eyebrows are large and prominent (fig 1).

The face is elongated with prominent "blubbery" lips and submucosal nodules present on the vermilion border, often laterally (fig 2). Oral manifestations, which are often the first clue to the syndrome in infancy or early childhood, include mucosal neuromas on the anterior dorsal surface of the tongue (fig 3). Mucosal neuromas of the tongue are almost pathognomonic in the presence of medullary thyroid carcinoma. Other oral features include palatal and pharyngeal neuromas, a high arched palate, and a prominent jaw.

Virtually all patients have medullary thyroid carcinoma which appears to be more aggressive than in MEN 2A, with average age at death around 21 years. ${ }^{6}$ Because of this reduced survival, around $50 \%$ of cases of MEN 2B are sporadic. Phaeochromocytoma are present in $50 \%$ of cases, of which half are multiple and often bilateral. This percentage increases with age, and is lower than in MEN 2A again because of the shorter life span. A small 
Table 1 Organ systems invoved in the MEN 2 syndromes

\begin{tabular}{lllllll}
\hline Disease & Thyroid (\%) & Adrenal (\%) & Parathyroid (\%) & Enteric ganglia (\%) & Mucosa (\%) & Skeletal (\%) \\
\hline MEN 2A & 100 & $50-70$ & 25 & Rare & - & - \\
FMTC & 100 & - & - & - & - & - \\
MEN 2B & 100 & 50 & - & 100 & - & - \\
HSCR & - & - & & & -100 & -
\end{tabular}

proportion of patients with undiagnosed phaeochromocytoma may die from a cardiovascular crisis perioperatively. ${ }^{67}$

There is a Marfanoid habitus in $75 \%$ of patients, ${ }^{8}$ often with proximal muscle wasting and weakness. Other musculoskeletal manifestations include kyphoscoliosis or lordosis, joint laxity, decreased subcutaneous fat, pes cavus, and slipped capital femoral epiphysis. ${ }^{6}$ Gastrointestinal problems include abdominal distension, megacolon, constipation, or diarrhoea resulting from diffuse ganglioneuromatosis. C cell hyperplasia of the thyroid cells causes calcitonin secretion and abnormal regulation of hormones allows release of histamine, serotonin, and prostaglandins among others. ${ }^{4}$

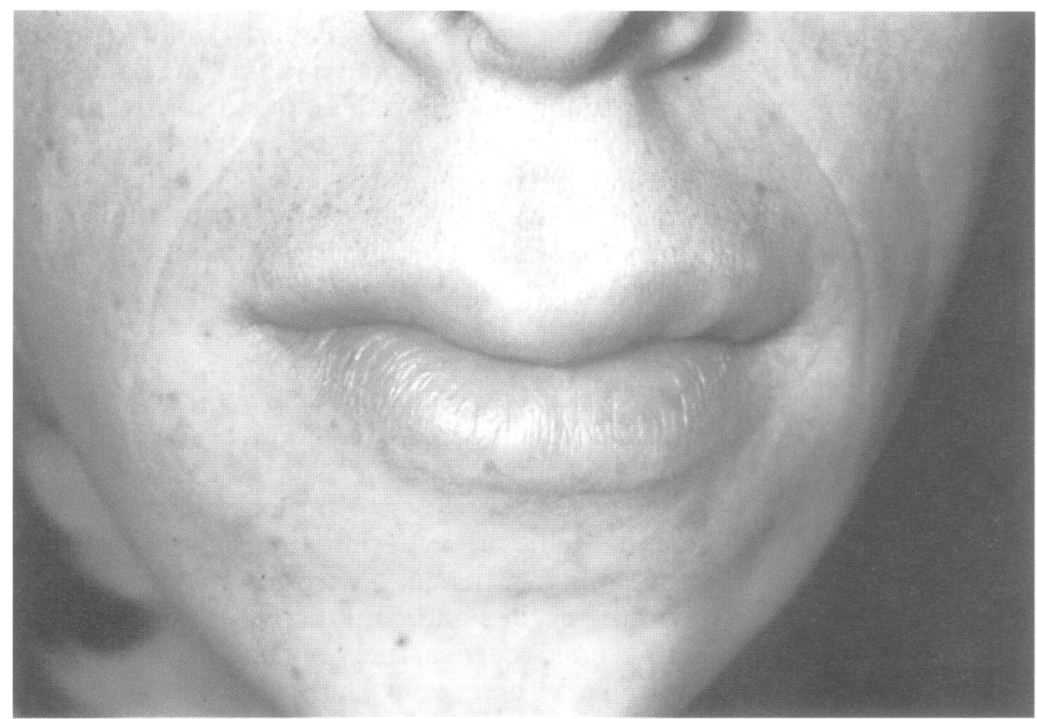

Figure 2 Subcutaneous thickening of the perioral region, with prominent "blubbery"lips and a submucosal nodule visible on the upper left lateral vermilion border.

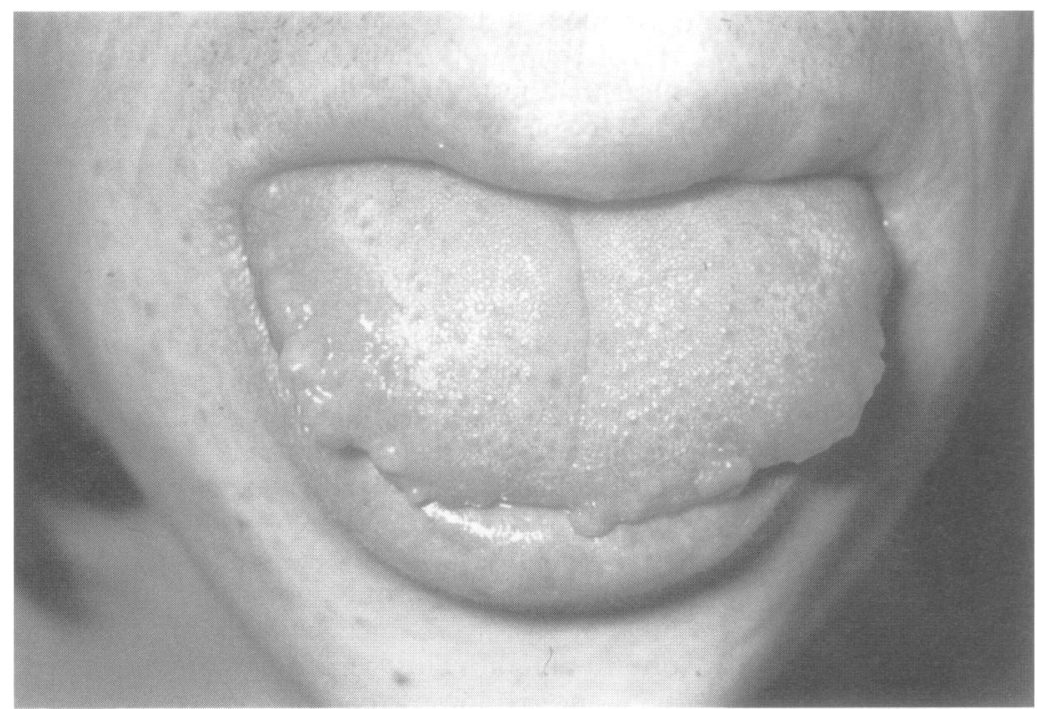

Figure 3 Multiple mucosal neuromas on the anterior dorsal surface of the tongue.

\section{Differential diagnosis}

Medullary thyroid carcinoma is seen in MEN type 2A (MTC, phaeochromocytoma or parathyroid adenoma or both, but without other neuroendocrine or dysmorphic features) and also familial medullary thyroid carcinoma (or FMTC, more than four patients within a family with MTC and no evidence of phaeochromocytoma on active screening). Familial autosomal dominant phaeochromocytoma may occur in isolation, or as part of other tumour syndromes including Von-Hippel Lindau disease and neurofibromatosis I and II. Familial intestinal pseudo-obstruction may occur as an autosomal dominant trait. ${ }^{9}$ Raised calcitonin levels, especially if stimulated by intravenous pentagastrin injection, are very suggestive of medullary thyroid carcinoma. CT of the adrenal glands may show the presence of phaeochromocytoma. Intestinal ganglioneuromatosis has a characteristic appearance on barium enema with alternating areas of dilatation and narrowing. ${ }^{10}$

\section{Aetiology and genetics}

MEN 2B is inherited as an autosomal dominant trait. Linkage to chromosome 10 was described in $1990 .{ }^{11}$ In 1993 , mutations in the proto-oncogene RET (REarranged during Transfection) were described in MEN 2A and FMTC, and it was suggested that MEN 2B could also be caused by a mutation within the RET oncogene. ${ }^{12} 13$ This was confirmed in $1994 .^{14-16}$ Over $95 \%$ of MEN $2 B$ patients have a specific point mutation at codon 918 in exon 16 of RET resulting in the replacement of methionine by threonine. One MEN 2B family has been shown not to have this mutation, although no mutation in this family has yet been identified. ${ }^{17}$ Another family has been shown to have an additional sequence variant resulting in a substitution of a tyrosine for a serine at position $922 .{ }^{18}$ The methionine at codon 918 is preserved in mouse proto-RET, ${ }^{19}$ and also in other receptor type tyrosine kinases, ${ }^{20}$ suggesting that this may be a crucial functional mutation.

Mutations in the RET gene cause four conditions, MEN 2A, FMTC, MEN 2B, and Hirschsprung disease (HSCR). HSCR is not a cancer syndrome, with only some cases caused by RET mutations. ${ }^{21}$ It is worth noting that overgrowth rather than absence of enteric ganglia is a prominent feature of MEN 2B. All four conditions involve expression of RET in embryonic thyroid C cells, adrenal medulla, parathyroid, and autonomic nerve plexi of the gut, ${ }^{22}$ which are all developmentally related. Most features of MEN 2B can thus be easily explained, but some of the skeletal features are not so easily explained by this model. 


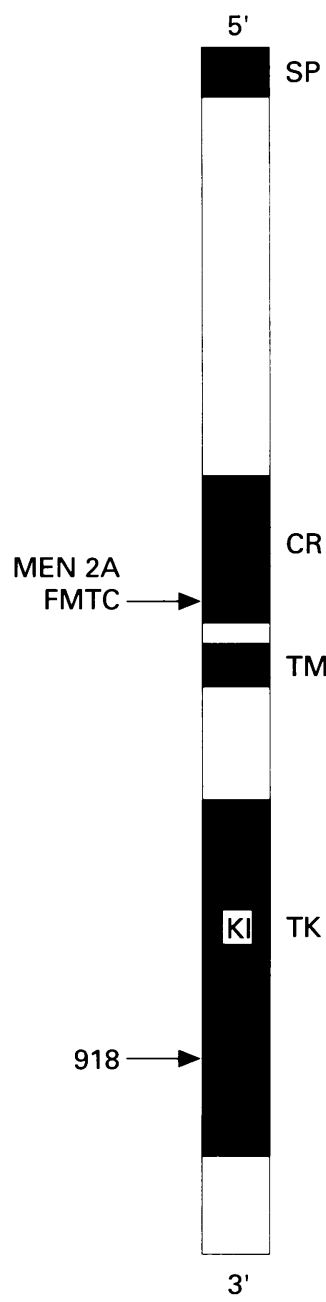

Figure 4 Diagram of the RET proto-oncogene showing the location of the majority of $M E N 2 A$ and FMTC mutations (arrow), and the site of the 918 $M E N 2 B$ mutation (arrow). Shaded areas represent the following: $S P$ = signal peptide, $C R=$ cysteine residues, $T M=$ transmembrane domain $T K=$ tyrosine kinase domain, $K I=$ kinase insert within the TK domain.
The structure of the RET gene is shown in fig 4 . The RET proto-oncogene contains 28 cysteine residues, and encodes a transmembrane receptor tyrosine kinase. Mutations associated with MEN 2A and FMTC involve cysteine residues in the extracellular domain of this receptor (fig 4). MEN $2 \mathrm{~B}$ is associated with the 918 mutation in the intracellular tyrosine kinase (TK) domain. There is some correlation between MEN 2A mutations and phenotype; mutations at codon 634 are more often associated with MEN 2A than FMTC and there is a predisposition to phaeochromocytoma and parathyroid disease at this site.

MEN $2 \mathrm{~B}$ is a much more aggressive condition than MEN 2A or FMTC. RET MEN 2B mutations alter the substrate specificity of RET, ${ }^{23}{ }^{24}$ which may result in alteration of RET activity at a post receptor level giving organ specific growth advantage. HSCR is associated with a variety of mutations scattered along the whole gene. RET mutations in HSCR appear to be recessive at the cellular level and RET appears to play a role in the development of the enteric nervous system. ${ }^{25}$

TK MEN 2A, like MEN 2B, has a gain of function, although MEN $2 \mathrm{~A}$ acts by converting RET into a transforming gene through ligand independent dimerisation, ${ }^{23}$ rather than a change in substrate specificity. In normal RET, ligand binding is followed by receptor dimerisation and activation of the TK domain. The RET ligand has not yet been identified but the MEN 2B mutation allows altered substrate phosphorylation independent of dimerisation. ${ }^{25}$ The catalytic specificity of protein kinases is critical for selective downstream signalling in cells. Receptor tyrosine kinases preferentially phosphorylate peptides recognised by their own group III Src-homology-2 (SH2) domains. $^{24}$ These domains recognise phosphotyrosine in a specific sequence context. The 918 mutation in MEN 2B is in a region of domain VIII that is responsible for peptide substrate selectivity; this mutation affects enzymatic activity and its interaction with different substrates. The wild type RET protein has a methionine at residue 918 ; mutation to a threonine causes preferential phosphorylation similar to $\mathrm{SH} 2$ containing protein tyrosine kinases. ${ }^{24}$ Other studies using biochemical analysis of the RET MEN 2B protein show a greater increase in autophosphorylation and TK activity than in the wild type, ${ }^{25}$ supporting a gain of function for this mutation.

The MEN 2B mutation differs in function from MEN 2A mutations. Transfection of RET in NIH 3T3 cell fibroblasts shows qualitatively and quantitatively altered RET catalytic properties in MEN $2 \mathrm{~B},{ }^{23}$ with MEN 2A showing less autophosphorylation. This confirms differential phosphorylation in the MEN $2 \mathrm{~B}$ transfectants and establishes that mutations in MEN 2A and MEN 2B convert RET into a dominant transforming gene through oncogenic conversion rather than a loss of suppressor function. This shows that germline transmission of a dominant transforming gene can occur in a human cancer. The more extensive MEN 2B phenotype could be explained by tis- sue specific differences in substrates, each with a unique mitogenic potential. ${ }^{25}$

Although MEN 2A shows allelic heterogeneity, this is not seen in MEN $2 B$ because of the common 918 mutation. MEN 2B cases are de novo in $50 \%$, and parental origin is almost exclusively paternal. ${ }^{26}$ This is not unique in tumour syndromes; several, including Wilms tumour, bilateral retinoblastoma, osteosarcoma, and neurofibromatosis I, show a paternal origin predominance. ${ }^{27}$ Some syndromes, such as Cowden syndrome, ${ }^{28}$ appear to show more severe expression through maternal transmission.

Another unusual feature for an "autosomal dominant" disease is that no distortion of the sex ratio in offspring is seen with paternally inherited MEN 2B, but maternally inherited alleles result in twice as many affected males as females. ${ }^{26}$ This is the opposite to that found in bilateral retinoblastoma cases. Explanations for this observation could include an additional disease associated gene or an embryonic lethal effect. ${ }^{29}$ Not enough pieces of the jigsaw are as yet available to see the whole solution clearly.

\section{Management}

All people at risk or suspected of having MEN $2 B$ should have mutational analysis for the RET gene as early as possible. In most cases this will provide presymptomatic diagnosis, or confirm the diagnosis. Prophylactic total thyroidectomy ${ }^{30}$ is advocated for people who are shown to inherit the mutation. The ideal age for surgery is preferably before the age of 4 years, ${ }^{31}$ as medullary thyroid carcinomas in MEN 2B are particularly aggressive and metastatic spread may occur before the age of 10 . Continued follow up of all affected or gene "positive" subjects should include annual screening for both medullary cancer by basal or stimulated calcitonin, and for phaeochromocytoma by standard urine and imaging techniques. ${ }^{30}$ The identification of the underlying molecular and biochemical mechanisms of RET activation above will be used in future therapeutic strategies.

1 Wagenmann A. Multiple neurome des auges und der Zunge. Ber Dtsch Opthalmol Ges 1922;43:282-5.

2 Froboese C. Das aus markhaltigen nervenfascern bestehende gangliezellenlose echte neurom in rankenformzugleich ein beitrag zu den nervosen Geschwulsten der zugleich ein beitrag zu den nervosen Geschwulsten der zunge und des auge

3 Williams ED, Pollock DJ. Multiple mucosal neuromata with endocrine tumours: a syndrome allied to Von Recklinghausen's disease. F Pathol Bacteriol 1966;91:71-80

4 Gorlin RJ, Vickers RA. Multiple mucosal neuromas, pheochromocytoma, medullary carcinoma of the thyroid and marfanoid body build with muscle wasting. $\mathrm{Re}$ examination of a syndrome of neural crest migration. Birth Defects 1971;7(6):69-72.

5 Nasir MA, Yee RW, Piest KL, et al. Multiple endocrine neoplasia type III. Cornea 1991;10:454-9.

6 Saltzman CL, Herzenberg JE, Phillips WA, et al. Thick lips, bumpy tongue, and slipped capital femoral epiphysis - a deadly combination. $\mathcal{F}$ Pediatr Orthop 1988;8:219-22.

7 Morrison PJ, Nevin NC, Hughes AE, Hadden DR, Russel CFJ. Presymptomatic screening in MEN 2A with linked CFJ. Presymptomatic screening in $M$

8 Bard LA. Genetic counseling of families with Marfan syndrome and other disorders showing a marfanoid habitus. Ophthalmology 1979;86:1764-93.

9 Roy AD, Bharucha H, Nevin NC, Odling-Smee GW Idiopathic intestinal pseudo-obstruction: a familial visceral neuropathy. Clin Genet 1980;18:291-7.

10 Anderson TE, Speckmann TJ, Schwartz SS. Roentgen findings in intestinal ganglioneuromatosis. Its association with medullary thyroid carcinoma and phaeochromocytoma. Radiology 1971;101:93-6. 
11 Norum RA, Lafreniere RG, O'Neal LW, et al. Linkage of th multiple endocrine neoplasia type 2B gene (MEN2B) to chromosome 10 markers linked to MEN2A. Genomics 1990;8:313-17.

12 Mulligan LM, Kwok JBJ, Healey CS, et al. Germ-line mutations of the RET proto-oncogene in multiple endocrine neoplasia type 2A. Nature 1993;363:458-60.

13 Donis-Keller H, Dou S, Chi D, et al. Mutations in the RET proto-oncogene are associated with MEN 2A and FMTC. Hum Mol Genet 1993;2:851-6.

14 Carlson KM, Dou S, Chi D, et al. Single missense mutation in the tyrosine kinase catalytic domain of the RET protooncogene is associated with multiple endocrine neoplasia oncogene is associated with multiple endocrine neopl
type 2b. Proc Natl Acad Sci USA 1994;91:1579-83.

15 Eng C, Smith DP, Mulligan LM, et al. Point mutation within Eng C, Smith DP, Mulligan LM, et al. Point mutation within multiple endocrine neoplasia type $2 \mathrm{~B}$ and related sporadic tumours. Hum Mol Genet 1994;3:237-41.

16 Hofstra RMW, Landsvater RM, Ceccerini I, et al. A mutation in the RET proto-oncogene associated with multiple endocrine neoplasia type $2 \mathrm{~B}$ and sporadic medullary thyroid carcinoma. Nature 1994;367:375-6.

17 Eng C, Toogood AA, Ponder BAJ, Shalet SM. A family with multiple endocrine neoplasia type $2 \mathrm{~B}$ which does not have a mutation at codon 918 of exon 16 of the RET proto-oncogene. 7 Endocrinol 1995;144 (suppl):P44.

18 Kitamura Y, Scarvarda N, Wells SA, Jackson CE, Goodfellow PJ. Two maternally derived missense mutations in the tyrosine kinase domain of the RET protooncogene in tyrosine kinase domain of the RET protooncogene in a patient with

19 Iwamoto T, Taniguchi T, Asai N, Ohkusin K, Makashima I, Takahashi M. cDNA cloning of mouse ret proto-oncogen and its sequence similarity to the cadherin superfamily. Oncogene 1993;8:1087-91.
20 Hanks SK, Quinn AM, Hunter T. The protein kinase fam政 lytic domains. Science 1988;241:42-52.

21 Romeo G, Ronchetto P, Luo Y, et al. Point mutations affecting the tyrosine kinase domain of the RET proto-oncogene in Hirschprung's disease. Nature 1994;367:377-8.

22 Pachnis V, Mankoo B, Costantini F. Expression of the c-ret proto-oncogene during mouse embryogenesis. Development 1993;119:1005-17.

23 Santoro M, Carlomagno F, Romano A, et al. Activation of RET as a dominant transforming gene by germline muta-

24 Songyang Z, Carraway KL, Eck MJ, et al. Catalytic specificity of protein tyrosine kinases is critical for selective city of protein tyrosine kinases is
signalling. Nature 1995;373:536-89.

25 Goodfellow PJ, Wells SA. RET gene and its implications for cancer. F Natl Cancer Inst 1995;87:1515-23.

26 Carlson KM, Bracamontes J, Jackson CE, et al. Parent of origin effects in multiple endocrine neoplasia type 2B. Am f Hum Genet 1994;55:1076-82.

27 Sapienza C. Parental origin effects, genome imprinting, and sex ratio distortion: double or nothing? Am $¥$ Hum Genet 1994;55:1073-5.

28 Hanssen AMN, Fryns JP. Cowden syndrome. $\mathcal{F}$ Med Gene 1995;32:117-19.

29 Naumova A, Sapienza C. The genetics of retinoblastoma revisited. Am f Hum Genet 1994;54:264-73.

30 Morrison PJ, Hadden DR, Hughes AE, Russell CFJ, Nevin NC. Gene probe analysis in an informative family with the MEN2A syndrome. Improvement in carrier risk estimations. $Q$ F Med 1991;78:597-603.

31 Utiger RD. Medullary thyroid carcinoma, genes and the prevention of cancer. N Engl F Med 1994;331:870-1. 